\title{
Naked Methodology: Baring It All for a Realistic Account of Marine Social Science
}

\author{
Kristen Ounanian
}

\subsection{Introduction}

Like others, I could have submitted an immaculate version of my $\mathrm{PhD}$ methodology, skirting the realities of revised plans and smoothing over the imperfections, but such an action would perpetuate unrealistic expectations for other social scientists. Writing openly about the challenges of a research project introduces a vulnerability, especially for a (then) doctoral candidate looking for acceptance into the ranks of academia. Nevertheless, baring it all reveals what research really looks like. Adapted from that work, I describe the evolution of my $\mathrm{PhD}$ research and expose the miscalculations and course corrections often glossed over. The chapter delineates the initial formulation of my $\mathrm{PhD}$ research design and methodology and why the original data collection and analytical framework did not hold. It pushes the envelope to include reflections and realizations, to give a more realistic portrayal of what happened en route to

K. Ounanian $(\bowtie)$

Centre for Blue Governance, Aalborg University, Aalborg, Denmark e-mail: kristen@plan.aau.dk 
the study's conclusions. Such transparency can hopefully reassure fellow researchers and create a space for more reflective and reflexive discussions of social science research in applied marine and fisheries contexts.

First, I outline how the project was conceived as a mixed methods approach with both qualitative and quantitative methods, including a testable hypothesis. I then recount the series of realizations of why it was best to eliminate the quantitative component - a questionnaire using the Factorial Survey Approach (FSA)—and how the project evolved into a qualitative macroethnography or multi-site ethnography. Secondly, I reflect on the 'bricolage' in this project and explain how the emancipation from the mixed methods framework, and my embrace of an inductive qualitative epistemology, ushered the project to its ultimate success. Finally, I consider our collective tendency in the (social) sciences to conceal the imperfections of field research, thus obscuring the insights gained from situations when things do not go according to plan.

\subsection{Evolution from Mixed Methods to Qualitative Macroethnography}

\subsubsection{The Initial Mixed Methods Research Design}

The project centred on a multiple case study design comparing coastal communities undergoing transition and manifestations of fisheries dependence in the regions of Northern Jutland, Denmark, and New England, United States. At the start of the project, and like many researchers embarking on their studies, I struggled to contain its scope. I wanted to not only look into changes in fisheries policies but also set them in the context of wider economic, social, and cultural changes. I feared going into the communities with preconceived ideas of important drivers or relevant issues, but finding that these were not salient. To avoid such a top-down research agenda, an inductive approach best suited the project. Although I could identify my alignment with inductive approaches, at that juncture I struggled to write a proposal with solely qualitative methods. As an interdisciplinary PhD student, who drew primarily from social science, I was hesitant to do solely qualitative research for reasons I further elaborate later. 
I settled on a mixed methods approach (Creswell 2014), interviewing key informants and community residents to build a survey instrument for wider distribution. To provide evidence of the initial motivation and structure of the research project, which would ultimately be amended midstream, I include excerpts from my dissertation proposal in Box 2.1.

\section{Box 2.1 Excerpts from Dissertation Proposal, Written in January 2013}

The empirical work will begin in Denmark with roughly eight to ten interviews in the three case communities and their two larger municipalities in order to vet relevant drivers of change generated initially through literature.

The final component of the empirical methods is a survey of residents in the American and Danish communities. As with many surveys, the purpose is to broaden from the case-specific narratives and identify patterns in preferences and opinions among participants with shared characteristics. Furthermore, the various strategic scenarios developed in the second stage will provide a means by which to elicit preferences in a more concrete and tangible way as opposed to single dimensions.

While the Danish cases will provide the material to develop the survey and its vignettes, interviews with community members will be included for the American cases to understand local context, identify shared experiences and themes, and develop a research relationship that will improve response rates for the survey.

I hypothesize that a community's mode of fisheries dependence will influence its adaptation strategies during periods of economic and social transition. To explore and test this hypothesis I will answer the following research questions:

1. How does fisheries dependence manifest in coastal communities today?

2. How do different types of coastal communities cope or navigate change during economic and social transitions?

The interviews were to identify themes and discern which social, cultural, and economic phenomena were most relevant. I conducted the semi-structured interviews with key informants in each community, following an interview protocol focused on fisheries management, local engagement with fisheries, and change within the community. In turn, the survey would allow me to test the outlined hypothesis that a community's mode of fisheries dependence would influence its adaptation strategies during periods of economic and social transition. It consisted of a 
questionnaire of residents in the American and Danish communities. As with many surveys, the purpose was to broaden from the case-specific narratives and identify patterns in preferences and opinions among participants with shared characteristics. The survey would provide a means of comparing communities at the aggregate level, but also enable insight into divisions within communities or linkages of groups across communities, in order to develop a typology of fisheries dependence. In addition to covering participant demographics, relationships to the fishing industry, and personal values concerning openness to change and traditionalism (Schwartz et al. 2012; Stern et al. 1998), the survey featured vignettes, brief narratives of particular events or circumstances, to address the two central themes of fisheries dependence and transition. Moreover, the vignettes followed an innovative method, the FSA, which I will elaborate on below. The survey was available in both English and Danish and totalled seventy-eight individual questions. There were six case study sites: three cases in northern Denmark (Hirtshals; Løkken; and Thorupstrand) and three parallel cases in the United States (New Bedford, Massachusetts; Provincetown, Massachusetts; and Cutler, Maine). At the start of the research I was living and studying in Aalborg, Denmark; I was scheduled to return to Rhode Island, United States, in fulfilment of my PhD in July 2014.

Disentangling what drives people's decisions poses challenges in social science research because certain social phenomena are often correlated. Take, for example, the relationship between housing property values and the performance of local school districts, which makes it difficult to determine the motivations for neighbourhood preference (Wallander 2009; Heise 2010). Additionally, research participants are not always conscious of the reasons behind their choices or the weight of one reason over another (Wallander 2009). The FSA allows researchers to elicit positive beliefs, normative judgements, and/or intended actions, by independently manipulating the level or magnitude of a select number of dimensions or independent variables within a set storyline or vignette (Wallander 2009; Rossi and Anderson 1982). In my research it offered the prospect to be able to randomly and orthogonally vary dimensions and their levels in order to uncover relationships to dependent constructs of fisheries dependence and transition (Taylor 2006). Furthermore, the use of vignettes provided a means to gauging survey participants' judgements and avoided social desirability bias in the responses (Wallander 2009). 


\subsubsection{Applying the FSA: Realizations in the Field}

FSA offered a potentially exciting and innovative means to investigate the concept of fisheries dependence. My intention was to present survey respondents with a brief, fictional description of a coastal community in which I would independently vary certain characteristics (or dimensions). I based those variables on the initial findings of the interviews in Northern Jutland. Upon reading the vignette, respondents were first asked to determine whether they considered the described community to be fisheries dependent and then to prescribe the best coping strategy under the circumstances presented in the vignette. Rather than presenting complete real-world examples, where geographic connections, level of fisheries engagement, and community economic health are often intertwined, FSA allowed me to vary the levels and dimensions independently. I could both connect the dimensions in the vignettes to the respondent's assessment of whether the described community was dependent or not and examine if there were patterns or correlations between community attributes and the suggested coping strategy. To make this more concrete, Box 2.2 includes the vignette with all dimension levels in brackets.

\section{Box 2.2 Full Vignette Text Displaying All Possible Dimensions and Levels}

Quahaugansett is a community on the coast of New England with a history in fishing and maritime trades. It takes [less/more] than forty-five minutes to drive from here to a major city. The community is [well/poorly] located as a land-sea transportation hub. In the past, Quahaugansett has had an active fishing fleet, but the number of boats has shrunk over the years. Residents of the community prefer that their fishing fleet be [comprised of small-scale boats for sustainability reasons/active and visible because they enjoy visiting the harbour/profitable and economically productive regardless of vessel size]. However, the fishing fleet is under pressure due to [lack of profitability/BLANK] [lack of interest from young people/BLANK] [other job opportunities outside the fishery/BLANK]. Many of the local maritime businesses [struggle to stay open/thrive] because of the level of business generated from the fishing fleet and other sectors. Apart from fishing, Quahaugansett has developed [one other industry/many other industries] with [little/large] success. 
The participants were then asked to prescribe what the community should do under the circumstances, if they lived there, with the following options:

If you lived here, what do you think the community should do?
A. Expand the fishing industry by encouraging new recruitment of the fleet
B. Maintain the fishing industry as it is currently
C. Adapt by letting fishing continue on its current path, but seeking other economic opportunities as they arise
D. Abandon fishing to pursue other industries/activities
E. Accept that things are changing and nothing can be done other than to leave the community
F. None of the above, please specify:

With this question, I used literature and information gained from the initial interviews, to draw a spectrum of responses ranging from full embrace of fishing - Expand the fishing industry by encouraging new recruitment of the fleet - to the complete retreat (and admittedly, hopelessness) embodied in the final option-Accept that things are changing and nothing can be done other than to leave the community. In between those embrace and retreat poles, three options covered strategies of maintaining, adapting, and abandoning fishing.

Doing an FSA study requires multiple versions of questionnaires with independently generated combinations of dimensions and vignettes. In my example, with 8 dimensions with 2 levels and 1 dimension with 3 levels, the object universe ${ }^{1}$ is $768\left(2^{\wedge} 8 \times 3^{\wedge} 1\right)$. Due to 3 dummy variables (presence of a condition or not), the total number of legitimate vignettes reduced from 768 to 672 . Each survey included 5 vignettes totalling 135 unique surveys. Due to the demographics of the communities (e.g. age and occupation), paper and pen questionnaires were chosen over an online version. In addition, programming the randomization and

\footnotetext{
${ }^{1}$ The object universe represents the full set of possible combinations of dimension levels and is calculated by multiplying the number of levels for each dimension.
} 
distribution of the vignettes would have required complicated coding in an online survey.

In addition, some questions were included in the survey to assess the degree of traditionalism and openness to change in the communities. Recognizing later that these questions offered little insight, I wished I had chosen to eliminate them from the survey. It would have shortened its length, which was inevitably necessary. Oftentimes, there is a fear when designing a survey that one will omit a critical question-or ten critical questions - and thus everything (and the kitchen sink) ends up being included. While there were other issues with the survey, I would have advised myself that less is more and to keep the survey simpler, especially when the vignettes were the most important part.

The survey was reviewed and tested by a group of persons from a coastal community in Northern Jutland, which was not one of the three cases. In addition, two colleagues with ties to the communities of Hirtshals and Thorupstrand reviewed and commented on the questionnaire. Apart from small text edits in the vignettes, from the pilot testing it seemed that some explanation of the vignette might help respondents better handle the questions. With a strategy of seeking residents in the communities through meetings and local organizations, I prepared a brief presentation to walk participants through an example of the vignette to help them better understand what they were being asked to do.

Soliciting participants to do the survey proved very difficult. Concerned with low response rates and difficulties in procuring addresses for people living in the communities, I decided that distribution at a community forum would be the best approach. In Hirtshals, we invited participants to an open meeting advertised with the help of local contacts and organizations in the community. At the first (attempted) meeting, with support of four different local institutions, only two people came (the parents of a fellow PhD student). That was disheartening. I regrouped, took another month to spread the word, and hit the streets posting flyers in shop windows. I even did a radio spot with the local radio station (speaking Danish—not my native language), encouraging people to come to the meeting and the local news website ran two stories on the meeting. And when the (second) meeting came around, there were about thirty people in the audience. 
At the meeting, I presented the project to those gathered and explained the survey's format walking through an example vignette. Due to this procedure, I had the chance to observe the participants completing the survey. From that experience came some notable observations. First, people needed a minimum of twenty minutes to complete the survey and in some cases almost a half hour. Secondly, aware that some in the audience were fishermen, I could see those individuals struggling to read the vignette paragraphs, looking over to one another in solidarity. This was not an issue of rolling eyes or indications that the survey questions were senseless, but rather that I had vastly overestimated the population's comfort reading and responding to written questions. The room was silent. It was as though I was administering an exam. I felt guilty.

In addition to witnessing the challenge some members had completing the survey, I also realized that disseminating the surveys through these town meetings was time, labour, and resource intensive. Hirtshals was the community where I was best connected to key local leaders, with the ability to rally support from local institutions. I made some initial efforts in Løkken, but it was clear that I did not have sufficient support. Furthermore, at that particular time in late spring, people in the community were preparing for the onslaught of tourists and summer activities, hence a meeting about a research project and survey was not a high priority. And so, my strategy shifted to working through the contacts and distributing the survey as a snowball sample. Of course, this change had methodological implications, but having weighed the options and implications, this decision at least allowed me to reach people to complete the survey. Nonetheless, the success was minimal and those that did fill it out were largely over sixty years old. In addition, my stay in Denmark was coming to an end. I decided to put the survey on hold and re-evaluate.

Sometimes in research, decisions are made for you. Months passed after I had returned to the United States and the survey remained in limbo. I needed to evaluate the data I had from the Danish cases, which were predominately from one case site. Most concerning was that answers to the question, 'If you lived here, what do you think the community should do?' showed little variation in distribution regardless of the dimensions in the vignettes. Additionally, 'Part IV: Values' showed little or no variation and would likely not be insightful for drawing any conclusions. 
I considered removing sections of the survey and reworking the response options for the vignettes, but months kept passing and I had made few new discoveries as how to remedy the multiple problems-dissemination, the vignettes, and overall length — of the survey. Moreover, the complicated nature of analysing the vignette data appeared as an even more formidable challenge.

The standstill on determining what to do about the survey also arose from the difficulty of organizing the data from the vignettes and identifying a suitable way of regressing the dimensions. Each participant answered two questions for each of the five vignettes, as well as other questions in the survey. Thus, organizing the dataset required a panel data approach because each vignette essentially represented a different observation, as would be the case in a time series or longitudinal study. Based on the type of dependent variable represented in the vignette judgement, different statistical and regression techniques could have been applied, including analysis of variance, multiple regression, logistic regression, and simple means comparisons of dimensions (Wallander 2009; Heise 2010). In addition to the information generated from the dimensions in the vignette and the associated dependent variables, with demographic information from each participant this information can also be used to illuminate relationships. Atzmüller and Steiner (2010) highlight different analysis possibilities with FSA in terms of respondent-level and vignettelevel effects. They explain that a 'quantitative vignette study consists of two components: (a) a vignette experiment as the core element, and (b) a traditional survey for the parallel and supplementary measurement of additional respondent-specific analysis of vignette data' (Atzmüller and Steiner 2010, 128). Jasso (2006) similarly explains the method's three, multiple order equations that cover decisions, positive beliefs, and normative judgements, further highlighting the onion-like layers throughout. These layers require further problem-solving and planning for the analysis to begin.

In summary, in addition to the mounting difficulty of getting people to fill out the survey, it became clear that once the data were procured, analysis would not be straightforward, nor would preliminary results be immediate. Furthermore, the cases covered in the literature had fewer 
than nine dimensions. It became apparent that I had added difficulty and complexity on top of trying a method for the first time. Meanwhile, a growing amount of qualitative data required coding and analysis.

\subsubsection{Rather Than Saw Off Your Foot, Get New Shoes: Adopting a Multi-case Ethnographic Approach}

Although the survey required attention in terms of content and dissemination, the project was not at a standstill. I finished interviewing twentysix persons related to the three Danish communities - more than initially intended-and moved back to New England for doctoral studies and fieldwork in August 2014. I began interviews in New England in January 2015 and began to recognize the richness of the qualitative data and the time necessary to do justice to the interviews in the inductive, grounded theory approach I intended (Glaser and Strauss 1967). I faced a methodological trade-off. I had a survey that was not functioning as planned; I could put more effort and resources to it, but with the caveat that the results may not be compelling in the end. Moreover, with finite resources and time, attention to the survey would pull effort away from the qualitative analysis. On the other hand, the interviews were richer, but also broader thematically than anticipated, and required time to analyse the findings as a result of an open, inductive approach.

Nonetheless, the push of the survey and the pull of the interview data were in the same direction. Once it became clearer that doggedly pursuing the survey risked undermining the interviews, the project became a qualitative study, not a qualitative-quantitative mixed methods design. Ultimately, letting go of the survey and the attempt at using FSA in a novel setting was difficult, but the recognition that the qualitative material deserved the spotlight eased the decision. As the title of this section recommends, I decided that rather than saw off my foot because the methodological shoe did not fit, I would find new shoes, or a new research framework, that would allow me to run to the end of the project without discomfort. With the decision to eliminate the survey, out went the overall framework of the project, namely the hypothesis to be tested. The 
project became an example of inductive science, not an effort to use inductive approaches in the initial stage to inform a more deductive instrument like the survey. Becoming an entirely qualitative project enabled me to examine the narratives at play in the communities. In order to incorporate the various themes uncovered in the interviews, the project remained focused on the manifestations of fisheries dependence and the concept of transition, but also covered emerging themes such as authenticity.

In its final, evolved form, the project became a multiple case study design, exploring the topics of fisheries dependence and transition through qualitative methods. The interviews represent the principal method of data collection, but were supplemented by written materials and media produced by/for the communities or organizations in those communities related to fisheries, tourism, or other maritime sectors. In addition to semi-structured and informal interviews, I also visited all the communities in this study on a few different occasions. Participant observation is a fixture of many ethnographic accounts, but the level of participation may vary from researcher to researcher or project to project (Spradley 1980). I primarily practised passive participation, characterized by lower degree of interaction with locals, where the researcher maintains an 'outsider' role (Spradley 1980). Except for the Cutler case, I was able to visit all the communities in different seasons, to gauge the winter quiet and the summer hyperactivity and in some instances the shoulder seasons of fall and spring. Although ethnographic work often situates the researcher for an extended period of months in a single place, often a small village, I did not live in the communities I studied. I embodied the 'commuter' researcher in respect to participant observation methods (Musante 2015). Consequently, the depth of my knowledge of each case is not as great as if I had stayed for extended periods living among the people I interviewed. However, the experiences travelling to those locations, walking the streets, and attending festivities, all inform this work, just as they would for a more traditional ethnography.

Many of these communities hold festivals and events that relate to the fishing industry and I attended some of those occasions, writing field notes of my observations and experiences. In many instances, I conducted interviews in people's places of business or their homes, and thus got a 
glimpse into what Goffman (1959) would call the backstage of their work and lives. Additionally, I collected documents - in print and digital format-from newspapers, self-produced materials, books, plans, tourism brochures, websites, and social media that were relevant to the research. Moreover, some of the rhetoric and discourses employed in plans and materials offered another means of understanding the ongoing narratives of these communities around fishing, change, and economic development. At times, six cases seemed daunting and ill-advised, but the connections to be made to similar cases in two different national contexts $^{2}$ strengthened the work and helped extend conclusions beyond what they would have been from a single case study. This work may be called a 'macroethnography' because its extent reaches to multiple communities (Spradley 1980). Finally, because of the delineated interest in fisheries dependence and transition, the project represents a topic-oriented ethnography as opposed to accounts with a more general interest in the culture of a place and/or its people (Hymes 1978 in Spradley 1980). Therefore, to call the final project an ethnography stretches the bounds of the method slightly, but the project still encapsulated many of the strategies and tenets of ethnographic research.

\subsection{Post-hoc Reflections}

\subsubsection{Pressure to Prove Methodological Bilingualism}

At the risk of sounding like an evangelist, I am a believer in mixed methods. At the start of the project, I found it difficult to design a study, especially one that included a survey, without speaking with community members first about the issues salient to them. Additionally, I was not disciplined enough — nor confident enough in a qualitative-only studyto recognize that the plan to interview and survey six communities was

\footnotetext{
${ }^{2}$ I worked in both Northern Jutland and New England because of my unique circumstance of being a dual doctoral student, enrolled at both Aalborg University and University of Rhode Island, located in each respective region. One of my central motivations in doing this $\mathrm{PhD}$ was to compare these two regions and build a typology of fisheries dependence, necessitating more than a single case. Full elaboration of the project is available in Ounanian (2016).
} 
overambitious. Conceptually I stand by my plan to include a survey to test my hypothesis connecting mode of dependence and orientation towards change. However, my faith was tested and I decided that my grand ideals of having a mixed methods $\mathrm{PhD}$ thesis would not come to fruition. A survey can only provide insight if people fill it out. Aside from concerns of statistical power, effect size, and response rate, without sufficient numbers of people completing the survey, analysis would provide little if any findings.

I felt disappointed that the work I had done on the survey-its development, its translation, the meeting in Hirtshals, and so on-would not furnish results for the dissertation. In a number of respects, I stand by the ambition to do a mixed methods project and to incorporate an innovative survey technique. A move away from 'either/or' thinking towards 'and/more' perspectives (Flyvbjerg 2006) will only strengthen social sciences contributions to resource policy and the study of communities undergoing change. By advocating an 'and/more' approach, Flyvbjerg (2006) encourages social scientists to let questions lead methodological choice and encourages a plurality of methods. Nonetheless, mixed methods studies require financial support, time, and researcher capacities to develop instruments, collect data, analyse the results, and synthesize the findings, that are likely greater than those studies falling under a single epistemological paradigm. There is encouragement, or perhaps pressure, to become a methodologically bilingual social scientist able to employ both quantitative and qualitative methods, and the $\mathrm{PhD}$ thesis represents a primary forum to demonstrate one's abilities as a researcher. However, the expectation/ambition-self-imposed or not — to 'do it all' also primes fledgling researchers to feel pinned into initial thinking when confronting an (inevitable) methodological crisis. It can feel that changing course and deviating from the original plan is a defeat or a result of a personal deficit.

Additionally, the pressure to prove oneself as methodologically bilingual especially confronts marine social scientists, or even environmental social scientists more broadly, because of the dominance of inquiry on the natural and physical dynamics of the environment and their ecology. As the term marine social science gains popularity, we must reflect on its meaning and the particular combination of marine with social science. 
As an alumna of the University of Rhode Island's Department of Marine Affairs, to which four other authors in this volume are affiliated, my preference is for marine affairs as a term that encapsulates the study of people-individuals through to their collective institutions-and their use of and relationships to oceans, coasts, and marine environments. My preference stands with marine over maritime, ${ }^{3}$ the latter of which I confine to shipping, navigation, and naval activities, whereas the former encapsulates the environments where myriad cultural, social, economic, and political concerns are enacted. This long aside is to recognize that many of us converge, or are being corralled, under the marine social science tent, taking different pathways to its destination, but likely with a shared experience confronting questions over methodological rigour, whether from positivistic and quantitatively driven economists and natural scientists, or from 'pure' disciplinarians of anthropology, geography, history, political science, sociology, and so on. Marine social scientists traverse in multiple worlds, academic and applied, and thus the pressure to demonstrate depth and breadth of one's science literacy can be formidable.

\subsubsection{Methodological Bricolage}

Even with the support of my PhD supervisor to eliminate the survey and restructure the project's methodology, I was still concerned that those evaluating my work would be sceptical of the findings or my core abilities to conduct rigorous social science research. My concern largely came from the idea that research designs ought not to change in the middle of fieldwork or data collection. As I was working out how to write my methodology, I was inspired by the following to write a reflective methodology:

The structures of the research handbooks have to be reconciled with accounts of how research is actually carried out. Lower's (1977) analysis of the accounts in Hammond demonstrate that, with one exception, the proj-

\footnotetext{
${ }^{3}$ David Symes underlined this difference in understanding of the terms maritime and marine among American and European scholars in a presentation in 2010 in connection to the EU Common Fisheries Policy reform process.
} 
ects embarked upon by these distinguished researchers all reached a point of disruption where the original plan, the original project, the original rationale for the research suffered a breakdown, precipitating a crisis and requiring activities of what Lower calls theoretical "patchworking" or theoretical "bricolage" in order to repair the breakdown and to present an appearance of coherence in the work. Of course, if research is recognized to be a journey into the unknown rather than a task which can be fully specified and planned in advance, then such breakdowns look less surprising, and we can look (Lower suggests) at the patchworking as the injection of a creative element into the process. (Gherardi and Turner 2002, 84-85)

I had initially thought that the methodological problems I encountered were due to my own inadequacies; perhaps I had not been disciplined or clever enough to recognize that the FSA would not work in this context or that I could drown in the qualitative data alone. However, Gherardi and Turner (2002) enlightened me and helped me recognize one of the dirty secrets of research: not every research project goes exactly according to plan.

'Bricolage' ${ }^{4}$ is indeed a fitting description of the process or means by which I produced a meaningful PhD thesis, and subsequently published journal articles, based on a diverse range of qualitative data that I had collected and analysed through grounded theory (Glaser and Strauss 1967). The intention of a collage is indeed to produce a meaningful picture using multiple sources and perhaps materials or media that are not commonly combined. The process requires one to recognize scraps or remnants and rework these, or put disparate images and patterns alongside each other, to produce a meaningful image. Of course, social science, just like any science, differs from art, and seeks to adhere to principles of replication and validity. But those principles are often achieved through the explicit writing up of data collection methods and modes of analysis, not in steadfastly following a previously set-out plan.

\footnotetext{
${ }^{4} \mathrm{~A}$ French term, bricolage refers to the process of creating or constructing a piece of art, craft, or literature from a diverse range of things that happen to be available, or a work created by such a process. In French, the verb bricoler translates to 'fiddle, tinker' and, by extension, 'to make creative and resourceful use of whatever materials are at hand (regardless of their original purpose)' (http:// www.informationbricolage.com/information/).
} 


\subsubsection{Concealing Imperfections Obscures Insights}

Following a theme of this chapter and the quotation presented from Gherardi and Turner (2002), the perception of defeat when something does not go according to the original plan emerges from the propensity of social scientists to sweep these roadblocks and alterations aside and report only the successes and the final form of the research design in write ups of methodology. However, we can find solace in Nietschmann $(1979,1)$ :

Field research can be a profound human experience. Yet the accounts of many studies are written as if the investigation had taken place in a vacuum-as if the researcher suddenly had been teletransported to the site and, by means of clairvoyance or immaculate conceptual perception, had faultlessly initiated and completed the research project in one binding flash of academic ingenuity.

Let me tell you, it usually doesn't work this way, especially in foreign settings. Even though they are exorcised from articles and books, there are awkward, stumbling, agonizing, often humorous personal accounts and problems that give each research experience a special character and texture.

As earlier alluded, social science research faces concerns and calls for methodological rigor, especially in situations where natural science colleagues have either simplistic views of the field (e.g. 'Social science is just talking to people, which anyone can do') or they can be sceptical towards findings (especially in qualitative work) because such works may lack explicitly detailed methodologies or elucidation on data collection and analysis. Nevertheless, post-positivist social science, with its varied epistemologies and related methodologies, may be difficult to understand for natural science colleagues without prior exposure or appreciation that there are legitimate differences in epistemology and how research can be carried out. Therefore, I echo the calls from Gherardi and Turner (2002) and Nietschmann (1979) to say that increased transparency in the way the research was carried out, without glossing over the points of crisis or course corrections, will be meaningful to those working within, alongside, and outside the discipline. 
Furthermore, while social science is a science and not an art, the recognition of creativity and the creative process embedded in research deserves reflection. Famed dancer and choreographer, Twyla Tharp (2003) outlines a typology of failure in her book, The Creative Habit, and the paired remedies for such failures:

- Failure of skill? Then get to work

- Failure of concept? Then get out when you can

- Failure of judgement? Be mindful that your name is on the final product and you will answer for the lack of execution of unpopular decisions

- Failure of nerve? Get over feeling foolish

- Failure through repetition? Resist, do new things

- Failure from denial? Deal with it and change it

In the evolution of my project, I recognize almost all of these failures. As difficult as it is to admit it, there was an element in the failure of skill in my limitations on how to organize and analyse the FSA data. Nonetheless, the deeper failures of the project were more in line with failures of concept, nerve, and denial. With the failure of concept in the FSA and the mixed qualitative-quantitative methods design, I could have ignored the signs of trouble and found myself in a failure of denial, largely because of a failure of nerve. It was necessary to both get over the feeling of being foolish and deal with the problems and make changes. Tharp (2003, 221) writes of the importance of finding a 'win-win change' where 'you have to hack out something that doesn't work and replace it with something that does'. Reading Tharp three years after the completion of my $\mathrm{PhD}$ and in preparation for this chapter makes me even more confident that changing course was the right decision. Without the humility to admit to miscalculations, over ambitious plans, or failures of all sorts, we as social scientists risk settling into rote ways of doing research (i.e. failure through repetition). Especially in applied contexts like those of the marine domain, the field may not progress, or at least not as quickly as it could, with such reflections. 


\subsubsection{A Reflexive Approach to Researching Coastal Communities}

Seeing this chapter as part of a volume on reflective and reflexive methodologies in research on people and the sea, I close with points specific to undertaking research in coastal communities. In his feedback to this chapter (and using an apt metaphor for this volume), Jeremy Phillipson advised me to look beyond methodological failure, 'No skipper sees every empty haul as a failure, so why should we as researchers'! Indeed, there are insights to be gained through absence.

I begin with insights on the use of FSA in the particular context of the fishing community and amongst a wider population. FSA questionnaires are often presented to professionals familiar with the task of making a particular decision or judgement based on differing circumstances (e.g. nurses (Taylor 2006) and social workers (Wallander and Blomqvist 2008)), or to groups of graduate students, who have the earned reputation of doing just about anything in exchange for food. In contrast, employing this approach for a public, heterogeneous audience presented challenges in both recruitment and the quality of the answers provided. I tried to overcome some of those issues by walking through an example vignette with the group assembled in Hirtshals, but again with the realization that it was costly to continue with these meetings, and there was a risk that the vignettes would not be properly understood. Additionally, as illustrated by the Hirtshals meeting, the vignettes required a comfort with reading paragraph length texts (five in succession), which could be expected of professionals, but less so for the general population (Sauer et al. 2011).

In addition to the limitations of FSA specifically, the overall dissemination of a survey to a general population (i.e. residents in a community) requires serious resources for a meaningful response rate. In my experience, it felt that people were increasingly resistant towards answering questions (especially closed questions) in a questionnaire and seemed more inclined to speak in an interview. Of course, there are reasons to use a survey and ways to make it succeed, but as people's data and opinions are mined more and more by commercial entities, I believe there is a 
growing reluctance among the public to engage with such instruments even for non-profit research. Fishers can be especially frustrated by questionnaires, particularly if they suspect their answers will be used against their interests or if the questions and response options conflict with their understandings and experiences of the situation. In contrast, I found that people were curious and interested towards me and my project. They appreciated the forum that an interview provided both to answer questions I prepared and to expand and extend the discussion on what was meaningful to them.

Credible accounts require multiple sources, which are addressed through the different modes of data collection, but interpretive social science also encourages researchers to state their own biases and experiences for the reader to judge the account. This is especially important when using methods of observation as 'the place from which the observer observes' influences what is seen and thus reported (Musante 2015, 272). Although discussing the limitations of participant observation, Musante's (2015) point that fellow scholars should not ask whether a researcher is biased, but rather ask how the researcher is biased, has relevance to this qualitative study. Similarly, in the hermeneutic tradition, prejudice, understood as one's own experiences, cannot be avoided and thus is an integral part of knowledge (Schnegg 2015). Moreover, the encouragement to be open about one's perspective, personal attributes, education, and ontological perspective are important features of accounts from the field (Musante 2015; Bernard 2006).

To that end, I can assess the lens through which I see, even as I try to wipe the glass clean of unintended bias. I grew up in a small suburb of Boston, which makes me a New Englander but one with somewhat different experiences than those who grew up, lived in, moved to, or worked in New Bedford, Provincetown, and Cutler. Being an American puts me further outside of the experience of the Danes, but having lived in the country for four years at the time of research coloured the account differently than one written by a Danish citizen or someone who had just arrived. Lastly, my experiential profile fits the footloose, educated young woman living out the 'mobility-as-opportunity discourse' discussed in the literature (Norman and Power 2014). Thus, compared to the desire to remain in the same community from childhood, as voiced by some in 
these interviews, I represent in some ways the opposite, which requires reflexivity. Nonetheless, I would be remiss not to admit that like many researchers, I study places, societies, and cultures that I personally find captivating. Reflexivity is paramount as the impartial, objective scientist of positivism gives way to the 'passionate participant' of constructivism (Guba and Lincoln 1994).

\subsection{Conclusion}

As stated at the outset, this chapter aimed to outline the progression of discoveries and pitfalls that contributed to my project's evolution. When I began the research, I intended to employ mixed methods, combining initial qualitative interviewing and a closed, structured questionnaire to answer the research questions and test my hypothesis. Nonetheless, there was a point, or perhaps a period of disruption, that forced me to reevaluate the initial plan, jettison the quantitative component and the hypothesis, and embrace a fully qualitative work. The structure of a multiple case study design and the data collection methods of interviews and field observations remained from the original plan. Nevertheless, the emphasis on the qualitative data also allowed a broadening of themes and an interpretive epistemology in the work.

My hope is that those who have read this chapter come away with an understanding of what I did in the field, how I treated the data, and my epistemic orientations and limitations that result in the discussions and conclusions of the dissertation. In addition to those conventional insights of a methodology chapter, the detail outlined in this chapter also serves to portray an honest account of social science research in the field. The 'disruptions' I recount are not anomalies in the pursuit of social science research. However, oftentimes such breakdowns do not receive elaboration in methods sections or chapters, making them de facto non-existent. In bringing the 'disruption' and 'bricolage' to light, I hope that those undergoing their own moments of crisis in their research will be relieved to know such things happen and the key is to carry onward. 
Acknowledgements I wish to thank my co-editors, Madeleine Gustavsson, Carole S. White, and Jeremy Phillipson for their collegiality and camaraderie in this process. This chapter improved through constructive comments and edits from each of them at various points of its development. Finally, I would like to thank members of my PhD committee who were especially supportive of the original dissertation chapter's concept and development.

\section{References}

Atzmüller, Christiane, and Peter M. Steiner. 2010. Experimental Vignette Studies in Survey Research. Methodology: European Journal of Research Methods for the Behavioral and Social Sciences 6 (3): 128-138. https://doi. org/10.1027/1614-2241/a000014.

Bernard, H.Russell. 2006. Participant Observation. In Research Methods in Anthropology, 4th ed., 342-286. Oxford: AltaMira Press.

Creswell, John W. 2014. Research Design: Qualitative, Quantitative, and Mixed Methods Approaches. 4th ed. Thousand Oaks, CA: SAGE Publications.

Flyvbjerg, B. 2006. Five Misunderstandings About Case-Study Research. Qualitative Inquiry 12 (2): 219-245. https://doi. org/10.1177/1077800405284363.

Gherardi, Silvia, and Barry Turner. 2002. Real Men Don't Collect Soft Data. In The Qualitative Researcher's Companion, ed. A. Michael Huberman and Matthew B. Miles, 81-100. Thousand Oaks, CA: Sage Publications.

Glaser, Barney G., and Anselm L. Strauss. 1967. The Discovery of Grounded Theory: Strategies for Qualitative Research. Hawthorne, NY: Aldine de Gruyter. Goffman, Erving. 1959. The Presentation of Self in Everyday Life. New York: Anchor Books.

Guba, Egon G., and Yvonna S. Lincoln. 1994. Competing Paradigms in Qualitative Research. In Handbook of Qualitative Research, ed. Norman K. Denzin and Yvonna S. Lincoln, 105-117. Thousand Oaks, CA: Sage Publications.

Heise, David R. 2010. Surveys with Vignettes. In Surveying Cultures, 75-86. Hoboken, NJ: John Wiley \& Sons, Inc.

Jasso, G. 2006. Factorial Survey Methods for Studying Beliefs and Judgments. Sociological Methods \& Research 34 (3): 334-423. https://doi. org/10.1177/0049124105283121. 
Lower, A. 1977. Facts and Frameworks: Aspects of the Research Process. University of Birmingham.

Musante, Kathleen. 2015. Participant Observation. In Handbook of Methods in Cultural Anthropology, ed. H. Russell Bernard and Clarence C. Gravlee, 2nd ed., 251-292. New York: Rowman \& Littlefield.

Nietschmann, Bernard. 1979. The House at Cotton Tree. In Caribbean Edge: The Coming of Modern Times to Isolated People and Wildlife, 1-7. Indianapolis, IN: The Bobbs-Merrill Company, Inc.

Norman, Moss Edward, and Nicole Gerarda Power. 2014. Stuck between 'the Rock' and a Hard Place: Rural Crisis and Re-Imagining Rural Newfoundland Feminine Subjectivities. Gender, Place \& Culture 00 (March 2015): 1-17. https://doi.org/10.1080/0966369X.2013.855707.

Ounanian, Kristen. 2016. In Place of Fishing: Coastal Communities in Transition. University of Rhode Island; Aalborg University. https://doi.org/10.5278/ vbn.phd.engsci.00101.

Rossi, Peter H., and Andrew B. Anderson. 1982. The Factorial Survey Approach: An Introduction. In Measuring Social Judgments: The Factorial Survey Approach, ed. Peter H. Rossi and Steven L. Nock, 15-67. Beverly Hills, CA: Sage.

Sauer, Carsten, Katrin Auspurg, Thomas Hinz, and Stefan Liebig. 2011. The Application of Factorial Surveys in General Population Samples: The Effects of Respondent Age and Education on Response Times and Consistency. Survey Research Methods 5 (3): 89-102.

Schnegg, Michael. 2015. Epistemology: The Nature and Validation of Knowledge. In Handbook of Methods in Cultural Anthropology, ed. H. Russel Bernard and Clarence C. Gravlee, 2nd ed., 21-54. New York: Rowman \& Littlefield.

Schwartz, Shalom H., Jan Cieciuch, Michele Vecchione, Eldad Davidov, Ronald Fischer, Constanze Beierlein, Alice Ramos, et al. 2012. Refining the Theory of Basic Individual Values. Journal of Personality and Social Psychology 103 (4): 663-688. http://psycnet.apa.org/journals/psp/103/4/663.html.

Spradley, James P. 1980. Participant Observation. Toronto: Thomson Learning. Stern, P.C., T. Dietz, and G.A. Guagnano. 1998. A Brief Inventory of Values. Educational and Psychological Measurement 58 (6): 984-1001. https://doi. org/10.1177/0013164498058006008.

Taylor, Brian J. 2006. Factorial Surveys: Using Vignettes to Study Professional Judgement. British Journal of Social Work 36: 1187-1207. 
Tharp, Twyla. 2003. An 'A' in Failure. In The Creative Habit, 210-229. New York: Simon \& Schuster Paperbacks.

Wallander, Lisa. 2009. 25 Years of Factorial Surveys in Sociology: A Review. Social Science Research 38 (3): 505-520. http://www.sciencedirect.com/science/article/pii/S0049089X09000192.

Wallander, Lisa, and Jan Blomqvist. 2008. Modeling Ideal Treatment Recommendations: A Factorial Survey of Swedish Social Workers' Ideal Recommendations of Inpatient or Outpatient Treatment for Problem Substance Users. Journal of Social Service Research 35 (1): 47-64. https://doi. org/10.1080/01488370802477436.

Open Access This chapter is licensed under the terms of the Creative Commons Attribution 4.0 International License (http://creativecommons.org/licenses/ by/4.0/), which permits use, sharing, adaptation, distribution and reproduction in any medium or format, as long as you give appropriate credit to the original author(s) and the source, provide a link to the Creative Commons licence and indicate if changes were made.

The images or other third party material in this chapter are included in the chapter's Creative Commons licence, unless indicated otherwise in a credit line to the material. If material is not included in the chapter's Creative Commons licence and your intended use is not permitted by statutory regulation or exceeds the permitted use, you will need to obtain permission directly from the copyright holder.

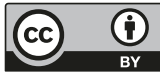

